AUTOR: Ulysses Paulino Albuquerque

DATA: outubro de 1996

LOCAL: Mestrado em Biologia Vegetal - UFPE

NÍVEL: Mestrado

BANCA EXAMINADORA: Laise de Holanda Cavalcanti Andrade (orientador) - UFPE

Geraldo Mariz - UFPE

Fernando Dantas de Araújo/Coordenador do PNE

Isabel Cristina Sobreira Machado - UFPE

Carmem Zieckel - UFRPE

RESUMO - Estudo da diversidade de espécies do gênero Ocimum L. no Nordeste do Brasil, com enfoque especial para Pernambuco. Analisou-se sua etnobotânica ligada às práticas dos descendentes culturais do africano no Brasil, uma vez que parte das espécies são originárias da África. Estudou-se morfologica e taxonomicamente espécimes coletados no campo e aqueles adquiridos em mercados públicos do Recife-PE, bem como material procedente de diferentes localidades do acervo de herbários brasileiros e do Royal Botanic Gardens. A análise etnobotânica foi baseada em observação participante, entrevistas semi-estruturadas e em inventário bibliográfico, para estabelecimento do paralelismo África-Brasil. Discute-se a morfologia das espécies e a variação de caracteres com relação ao movimento de plantas e cultivo; inclui-se, ainda, chaves para determinação dos táxons específicos reconhecidos, descrições e ilustrações, além de um tratamento mais minucioso quali-quantitativo da morfologia das núculas. Através da morfologia comparativa das plantas, $O$. americanum L. e $O$. basilicum L. podem ser distinguidas entre si. São reconhecidas três secçōes, às quais estão subordinadas as sete espécies ocorrentes na região: $O$. americanum L., $O$. basilicum L., $O$. gratissimum L., O. transamazonicum C. Pereira, O. minimum L. (Ocimum), O. campechianum Mill. (Gymnocimum) e O. tenuiflorum var. religiosum Albuquerque, $O$. campechianum var. pubescens Albuquerque e $O$. campechianum var. congestifolium Albuquerque. Os resultados indicam, entre outras coisas, que existe correspondência e paralelismo de usos de Ocimum entre África e Brasil, bem como na atribuição de etnômios às espécies, e que o colonizador europeu foi responsável pela introdução de $O$. americanum, $O$. basilicum, $O$. gratissimum e $O$. minimum no Brasil.

\title{
Universidade Federal Rural de Pernambuco
}

TítUlO: Estudos taxonômicos sobre a família Bombacaceae Humb., Bonpi. \& Kunth no Estado de AUTORA: Ana Luiza Du Bocage Neta

DATA:

LOCAL: Universidade Federal Rural de Pernambuco - UFRPE

NÍVEL: Mestrado

BANCA EXAMINADORA: Enide Eskinazi Leça (orientadora)

Geraldo Mariz - UFPE

Simon Joseph Mayo - RBG, Kew

RESUMO - O trabalho consiste de um estudo taxonômico sobre a família Bombaceae E. Kunth para o Estado de Pernambuco, Brasil. Baseou-se, fundamentalmente, na análise morfológica comparativa dos espécimes obtidos através de coletas realizadas no período de 1990 a 1993 e de material de herbário. Além das observações de campo, que foram essenciais para a determinação dos gêneros e espécies para Pernambuco, constatou-se a ocorrência de sete espécies distribuídas em seis gêneros: Bombacopsis retusa (Mart \& Zucc.). A. Robyns, Ceiba glaziovii (Kuntze) K. Schum., Eriotheca crenulaticalyx A. Robyns, Pachira aquatica Aubl, Pseudobombax marginatum (A. St. - Hil.,) A. Robyns Pseudobombax simplici- 
folium A. Robyns e Quararibea turbinata (S.W.) Poir, das quais Bombacopsis retusa e Pseudobombax marginatum são referidas pela primeira vez para Pernambuco. As espécies Ceiba glaziovii e Pseudobombax marginatum foram consideradas de ampla distribuição na área estudada, enquanto Bombacopsis retusa e Pseudobombax simplicifolium apresentaram distribuição bastante restrita. Pachira aquatica foi considerada como subespontânea. Apresentam-se descriçōes, comentários sobre morfologia, fenologia e distribuição geográfica, bem como ilustrações para cada espécie.

TítUlO: Aspectos ecológicos da margem de Sargassum do costão rochoso da Praia de Pedra do Xaréu - Cabo - PE - Brasil

AUTOR: Andrés Omar Mansilla Munoz

DATA: $\quad$ outubro de 1993

LOCAL: $\quad$ Universidade Federal Rural de Pernambuco - UFRPE

NÍVEL: Mestrado

BANCA EXAMINADORA: Sonia Maria Barreto Pereira (orientadora)

Leonor Costa Maia - UFRPE

Enide Eskinazi Leça

Zanon de Oliveira Passavante

RESUMO - Neste trabalho caracterizou-se a comunidade de Sargassum do costão rochoso de Pedra do Xaréu, Cabo - PE - Brasil. Na margem de Sargassum foi demarcada uma área de $15 \mathrm{~m} \mathrm{x} 4 \mathrm{~m}$, na qual foram realizadas coletas mensais, nas baixa - marés, nos períodos de janeiro e julho de 1992 . Foram coletadas e identificadas as macroalgas, realizadas contagens da macrofauna (artrópodos e gastrópodos) e determinada a biomassa $\left(\mathrm{g} / \mathrm{m}^{2}\right)$, frequência relativa $(\%)$ e recobrimento $(\%)$. Utilizou-se para amostragem uma circunferência de $50 \mathrm{~cm}^{2}$, com 30 repetiçōes aleatórias. A espécie dominante foi Sargassum polyceratium, que apresentou características morfológicas e reprodutivas típicas das espécies do gênero, quando coletadas em costōes com forte hidrodinamismo, com forte apressório, eixo principal, ramos primários, secundários e terciários bem desenvolvidos, ausência de flutuadores e ocorrência de plantas hermafroditas. As macroalgas de melhor ocorrência foram as da Divisão Rhodophyta (50\%), seguidas pelas Phaeophyta (37,31\%) e Chlorophyta (14,2\%). Algas como Dipterosiphonia sp., Hypnea musciformis e Fosliella sp. apresentaram-se sempre como epifitas de $S$. polyceratium. Apenas Amansia multifida, Laurencia papillosa e Laurencia sp. ocorreram como epilíticas, ao igual que as espécies da ordem Dictyotales, excetuandose Padina gymnospora e Spatoglossum schroederi.

TÍTULO: Morfologia polínica de Cactaceae das caatingas

AUTOR: Francisco de Assis Ribeiro dos Santos

DATA: outubro de 1993

LOCAL: $\quad$ Universidade Federal Rural de Pernambuco - UFRPE

NÍVEL: Mestrado

BANCA EXAMINADORA: José Luiz de Hamburgo Alves (orientador) - UFRPE

Terezinha de Sant'Ana Melhem - IBt/SP

Laíse de Holanda Cavalcanti Andrade - UFRPE

Hiroko Makino Watanabe - IBt/SP

RESUMO - O trabalho em questão foi precedido de um consistente levantamento bibliográfico sobre o que tem sido feito com relação á Palinologia, mas seu objetivo principal foi o estudo da morfologia polínica de 21 espécies de Cactaceae, distribuídas em 9 gêneros ocorrentes nas Caatingas do Estado de Pernambuco. Através da técnica da acetólise e métodos adequados e dos resultados inferidos da pesquisa, oferecer subsídios à taxonomia e contribuir para o conhecimento da flora polínica das Caatingas. A partir da análise dos caracteres morfológicos, as conclusões indicaram relacionamento de gênero à sub-familia, distinção 
morfológica e evolução intergenética; interrelacionamento genético e a nível de tribo, a estenopolinicidade existente entre gêneros e tribo, fatores genéticos consequentes de hibridação (poliploidia e hibridação), atuando em anomalia polínica de alguns gêneros; a morfologia do pólen das Cactaceae está intimamente adaptada à condição xérica das Caatingas; os caracteres polínicos e demais aspectos morfológicos das Cactaceae sofreram um processo de evolução heterobátmico.

TíTULO: Cultivo in vitro de cará-da-costa (Dioscorea cayenensis Lam.) - aspectos e condições AUTOR: $\quad$ Natoniel Franklin de Melo

DATA: $\quad$ março de 1994

LOCAL: Universidade Federal Rural de Pernambuco - UFRPE

NÍVEL: Mestrado

BANCA EXAMINADORA: Marcelo dos Santos Guerra Filho (orientador)

Tânia Maria Muniz de Arruda Falcão

Lilia Willadino A. de Oliveira

RESUMO - Neste trabalho foram testadas várias técnicas de cultivo in vitro em cará-da-costa (Dioscorea cayenensis Lam.) visando a micropropagação da espécie. Para isso, foram realizados vários ensaios empregando-se a cultura de segmentos nodais, cultura de meristemas, multiplicação das brotações produzidas in vitro, cultura de calos e o enraizamento in e ex vitro. Nas várias etapas os tecidos foram cultivados em meio básico de murashige e skoog, com pequenas alteraçōes, onde procurou-se encontrar as relações entre auxinas e citocininas adequadas para a proliferação da referida espécie. Com os resultados obtidos, notou-se que a relação auxina/citocinina não produziu diferenças significativas na cultura de segmentos nodais. Entretanto, na multiplicação das brotaçōes in vitro, esta relação apresentou diferenças altamente significativas, do ponto-de-vista estatístico. Neste caso, o uso de altas concentraçōes de cinetina e do ácido 3 - inaolilacético, teve um efeito tóxico, produzindo plantas com características atípicas da espécie. Enraizamento in e ex vitro foram obtidos, sobressaindose o primeiro caso, com cerca de $100 \%$ de plantas enraizadas. Organogênese foi obtida a partir da cultura de calos, na ausência de auxina e com 1 me/l de cinetina. Os meristemas cultivados in vitro não responderam a inaução do meio nutritivo empregado.

TíTULO: Cultura in vitro e comportamento em meio salino de cultivares de batata-doce (Ipomoea batatas (L.) Lam)

AUTORA: Oneide Ferreira de Andrade Castro

DATA: $\quad$ março de 1994

LOCAL: Universidade Federal Rural de Pernambuco - UFRPE

NÍVEL: Mestrado

BANCA EXAMINADORA: Tânia Maria Muniz de Arruda Falcão (orientador)

Lilia Willadino Andrade de Oliveira

Egídio Bezerra Neto

RESUMO - Os meristemas apicais foram inoculados no meio MS suplementado com: ANA + BAP; ANA + KIN + AG3; E ANA + BAP + AG3. As cultivares RC 1.8; MFT (Mãe de Família TAMBE); TR3, 473 e ARROBA produziram plântulas de alturas similares, porém com diferentes taxas de regeneração. A suplementação com $0,01 \mathrm{mg}$ de ANA/P + 1,0mg de BAP) Lé a mais recomendável para as cultivares ARROBA MFT, enquanto que a de $0,005 \mathrm{mg}$ de $A N A / L+0,25 \mathrm{mg}$ de $B A P+0,25 \mathrm{mg}$ de $A G 3 / L$ é a mais indicada para as cultivares TR3, 473 e RC 1.8. A micropropagação dessas plântulas através de segmentos nodais inoculados em meio MS contendo $1,0 \mathrm{mg}$ de $\mathrm{AG} 3 / \mathrm{L}$, não mostrou diferenças entre as cultivares. $\mathrm{Na}$ indução a calos de pecíolos de nove cultivares, inoculados em meio MS suplementado com 2,21 ou 1,0mg 
de 2,4-D/L combinado ou não com 0,25mg de BAP/L, observou-se difereças na taxa de regeneração e tamanho dos calos conforme a cultivar ou meio empregado, sendo a ARROBA a melhor cultivar e a suplementação com 2,21 mg de 2,4-D/L + 0,0025mg de BAP/L a mais recomendada. A vitória roxa não formou calos. Além disso, observou-se que o estresse salino comprometeu o crescimento dos calos, na seguinte ordem decrescente de tolerância à salinidade: arroba, co-roxa, RC 1.8, co-branca, TR3, Mãe de familia TAMBÉ, paulistinha e 473.

TítULO: Estudos taxonômicos dos representantes da ordem Dictyotales (Phaeophyta) da praia de Serrambi, Município de Ipojuca (Estado de Pernambuco-Brasil)

AUTORA: Airam Silva Lopes

DATA: abril de 1994

LOCAL: Universidade Federal Rural de Pernambuco - UFRPE

NÍVEL: Mestrado

BANCA EXAMINADORA: Enide Eskinazi Leça (orientador)

Laíse de Holanda C. Andrade - UFRPE

Cláudia C. Branco Chamixaes

RESUMO - Neste trabalho apresentam-se estudos taxonômicos da ordem Dictyotales (Phaeophyta), na praia de Serrambi, Município de Ipojuca, Estado de Pernambuco - Brasil. Neste local foram eleitas três estações: Illha de Froa (estação 1), Ponta de Serrambi (estação 2) e Foz do rio Macaraípe (estação 3). O material foi coletado mensalmente, no período de janeiro/1987 a julho/1988, com coletas complementares de fevereiro/1990 a novembro/1991. Foram identificadas 14 espécies, distribuídas em 5 gêneros, tendo sido feitas descrições, ilustrações, comentários taxonômicos, distribuição para o litoral brasileiro, chaves de identificação dos gêneros e espécies. São apresentados mapas de localização da área, das estações de coleta e distribuição das espécies do litoral brasileiro, bem como tabela de estado fértil, frequência de ocorrência, relação entre espécies hospedeiras e epífitas. O gênero Dictyota, com $57 \%$ do total, foi o melhor representado (8 espécies). Sendo referida pela primeira vez para Pernambuco a espécie Dictyota pardalis Kuetzing. As seguintes espécies foram consideradas muito frequentes na flora estudada: Dictyopteris delicatula, Dictyota cervicornis e Padina gymnospora. O gênero Dictyopteris apresentou-se como segundo representante desta ordem, com três espécies, sendo que Dictyopteris jolyana foi encontrada em apenas duas estações de coleta e como arribada.

TíTULO: Variabilidade genética em 29 populações de cubiu (Solanum topiro Humel. \& Bonpl. Solanaceae) avaliada na zona da mata do Estado de Pernambuco

AUTOR: Danilo Fernandes da Silva Filho

DATA: abril de 1994

LOCAL: Universidade Federal Rural de Pernambuco - UFRPE

NÍVEL: Mestrado

BANCA EXAMINADORA: Clodoaldo José da Anunciação Filho (orientador)

Mário de Andrade Lira

Margarida Agostinho Lemos

Hiroshi Noda

RESUMO - Avaliou-se a amplitude da variabilidade genética em 29 populações de cubiu do programa de melhoramento, Instituto Nacional de Pesquisas da Amazônia, INPA. O experimento foi conduzido na Estação Experimental da Empresa Pernambucana de Pesquisa Agropecuária, IPA, em Vitória de Santo Antâo, Estado de Pernambuco. Adotou-se o delineamento experiemental em blocos casualizados, com 4 repetições. Coletram-se dados referentes ao formato dos frutos, diâmetro do colo, altura da planta área, da folha, largura do fruto, comprimento do fruto, número total médio de frutos por planta, peso médio dos 
frutos, peso total de frutos, número de lóculos, espessura da polpa e teor de sólidos solúveis totais. A variabilidade encontrada nessas populaçōes na forma, tamanho, número e peso dos frutos, permitiu considerá-la um extraordinário material genético para ser aproveitado em programa de melhoramento. A análise de agrupamento pelo método de Tocher, usando a Distância Generalizada de Mahalanobis, agrupou as 29 populações em nove grupos diferentes. As populações procedentes de Arara, Benjamim Constant, Coari, Tarapoto e Iquitos, além de consideradas as mais divergentes, foram as que reuniram os melhores valores agronômicos, portanto, credenciando-se como possíveis progenitores em programa de melhoramento genético. A análise de trilha detectou que o número de frutos é o caráter mais influente na produção de cubiu.

TÍTULO: Resposta de cultivares de soja de diferentes ciclos vegetativos ao postássio

AUTOR: Hilton Morbeck Oliveira

DATA: $\quad$ maio de 1994

LOCAL: Universidade Federal Rural de Pernambuco - UFRPE

NÍVEL: Mestrado

BANCA EXAMINADORA: Joselito Sobreira Medeiros (orientador)

Carlos Alberto Oliveira Ventura

Clodoaldo José da Anunciação Filho

RESUMO - A soja é hoje uma das principais culturas da economia brasileira, sendo cultivada de norte a sul do país. Plantas de soja cultivares Seridó, Doko, Tropical e Cariri foram cultivadas em casa de vegetação da UFRPE, em vasos de PVC, contendo $10 \mathrm{~kg}$ de solo tipo Areias Quartzosas. Vasos com 3 plantas, quando foram submetidas a 3 diferentes níveis de potássio e 2 tipos de inoculantes, além da testemunha. A colheita foi efetuada aos 52 dias após o plantio. Os resultados mostraram que os níveis de potássio utilizados não aumentaram a quantidade de matéria seca na parte aérea da planta, nem afetaram a concentração de nitrogênio, assim como sua fixação. Todavia, o teor de potássio na parte aérea da planta teve resposta significativa para o componente linear nos níveis de potássio aplicados. Verificou-se que as estirpes introduzidas influenciaram nas quantidades de nitrogênio e potássio, devido ao aumento de matéria seca. Porém as estirpes nativas demonstraram uma tendência bastante promissora. A cultivar Cariri apresentou maior peso de nódulos e maior atividade da nitrogenase, porém não houve resposta em
relação ao crescimento.

TÍTULO: Interação genótipo $\mathrm{x}$ ambiente na cultura do algodoeiro herbáceo (Gossypium hirsutum $\mathrm{L}$.

AUTOR: $\quad$ Ivan Souto de Oliveira Junior

DATA: julho de 1994

LOCAL: Universidade Federal Rural de Pernambuco - UFRPE

NÍVEL: Mestrado

BANCA EXAMINADORA: Clodoaldo José A. Filho (orientador)

Mário de Andrade Lira

Elton Oliveira dos Santos

José Geraldo Eugênio de França

RESUMO - O presente trabalho teve por objetivo avaliar o comportamento de 15 genótipos de algodoeiro herbáceo nos municípios de Serra Talhada e Caruaru, nos anos de 1985 a 1989, visando identificar materiais com elevada produtividade, adaptabilidade e boas características tecnológicas da fibra. Para atingir estes objetivos, foram avaliados os seguintes parâmetros: produção de algodão em caroço, comprimento, finura e uniformidade da fibra. Cada parcela experimental foi constituída por duas fileiras de cinco metros de comprimento, no espaçamento de $1 \mathrm{~m} \times 0,2 \mathrm{~m}$, usando-se a densidade de plantio 
de duas plantas por cova. Em todos os ensaios foi utilizado o delineamento de blocos ao acaso com nove tratamentos e oito repetições. Os campos foram adubados com a fórmula NPK 10-30-0 em fundação e $30 \mathrm{~kg}$ de N/ha em cobertura, quando da realização do desbaste. Levando-se em conta a similaridade existente entre os ensaios, foram organizados dois grupos de experimentos, sendo cada um deles constituído pelos mesmos tratamentos. As análises conjuntas de variância dos grupos I e II mostraram efeitos significativos e altamente significativo para tratamentos, experimentos e interação tratamentos $\mathrm{x}$ experimentos na grande maioria dos parâmetros estudados, evidenciando que, tanto os genótipos como também os ambientes, mostraram ser diferentes e que os parâmetros estudados foram sensíveis aos ambientes.

TítULO: Família Rhodomelaceae (Ceramiales-Rhodophyta) na Praia de Serrambi-Pernambuco-

AUTORA: Adilma de L. Montenegro

DATA: $\quad$ setembro de 1994

LOCAL: $\quad$ Universidade Federal Rural de Pernambuco - UFRPE

NÍVEL: Mestrado

BANCA EXAMINADORA: Enide Eskinazi Leça (orientador)

José Zanon de Oliveira Passavante

Eurico Cabral de Oliveira Filho

RESUMO - Foram realizados estudos taxonômicos e ecológicos de representantes da família Rhodomelaceae na praia de Serrambi, Ipojuca-PE, entre $8^{\circ} 32^{\prime}$ e $8^{\circ} 34^{\prime}$ de latitude sul e $35^{\circ} 00^{\prime}$ e $35^{\circ} 01$ de longitude Oeste. Amostras foram coletadas em 3 estações fixas (platô e bordas) em área de formação recifal. Procedeu-se os estudos morfológicos e anatômicos com auxílio de estereomicroscópio e microscópio binocular. O estudo anatômico das características vegetativas e reprodutivas das espécies foi realizado com cortes a mão livre e corados, quando necessário. Foram identificados 10 gêneros e 14 espécies: Acanthophora spicifera, Amansia multifida, Bryothamnion seaforthii, B. triquetrum, Digenia simplex, Diptcrosiphonia dendritica, Enantiocladia dupereyi, Herposiphonia tenella, Laurencia flagellifera, $L$, papillosa, Laurencia sp.. Polisiphonia subtilissima e Vidalia obtusiloba. Todas as espécies foram descritas, ilustradas, sendo apresentados também dados de sua distribuição no local de coleta e no litoral brasileiro, relação das epífitas e hospedeiro e discussão baseada na literatura especializada. Laurencia papillosa e Acantophora spicifera destacaram-se como mais frequentes. Plantas femininas de Bryothamnion seaforthii e Digenia simplex estāo sendo referidas pela $1^{2}$ vez para o litoral brasileiro. Laurencia sp. é provavelmente um novo táxon para a Ciência.

TítULO: Aspectos ecológicos e do desenvolvimento e viabilidade de aproveitamento da Typha domingensis Pers. no perímetro irrigado do Moxotó-Ibimirim-PE-Brasil

AUTORA: Margareth Grillo Teixeira

DATA: outubro de 1994

LOCAL: Universidade Federal Rural de Pernambuco - UFRPE

NIVEL: Mestrado

BANCA EXAMINADORA: Francisco de Assis Esteves (orientador)

Emídio Cantídio de O. Filho

Rosa Maria de Morais Guedes

Lilia W. A. de Oliveira

RESUMO - A espécie T. domingensis foi estudada no perímetro irrigado do Moxotó (Ibimirim - PE), em setores dos drenos secundários e terciários e em uma área de lagoa. Considerando os drenos como transectos, foi coletada a planta inteira (rizoma e parte área), em parcelas de $1 \mathrm{~m}^{2}$, determinada a altura da 
parte aérea, número de rametas $/ \mathrm{m}^{2}$, peso da matéria verde e da matéria seca e do rizoma e a fase fenológica dos rametas. Para acompanhar o processo de regeneração, foi cortada a parte aérea em diferentes alturas, desde o nível da água, em quatro unidades amostais de seis metros de extensão. A viabilidade de aproveitamento econômico de parte da planta em testes artesenais, culinários, fitoquímicos e industrial para a produção de papel, foi também analisado. A espécie apresentou altura média de $281 \mathrm{~cm}, 30,3$ rametas $/ \mathrm{m}^{2}$ e 38,2 rametas mortos $/ \mathrm{m}^{2}$, com emissão constante de rametas jovens e dois ciclos anuais de dispersão das sementes, tendo apresentado apenas $10 \%$ de rametas férteis $\mathrm{m}^{2}$. A reprodução vegetativa, responsável pelo processo de infestação dos drenos apresentou rizomas com formação de coroas meristmáticas apenas nas partes mais secas dos taludes dos drenos. O peso da matéria verde da parte aérea $(9,147$ $\mathrm{g} / \mathrm{m}^{2}$ e $1562,7 \mathrm{~g} / \mathrm{m}^{2}$ de peso da matéria seca da parte aérea e do rizoma, respectivamente. A variação sazonal climática, edáfica ou hidrológica no perímetro irigado foi insignificante, tendo os teores nutricionais da água destacando-se como os parâmetros de maior influência no desenvolvimento da planta. $\mathrm{O}$ solo de textura mais arenosa favoreceu o desenvolvimento em altura e longevidade da espécie, tendo a profundidade da água e a permanência do material morto dentro da população dificultado a exposição do rizoma a luminosidade, reduzindo, em consequiência, a emergência de novos rametas. A espécie apresentou redução de tamanho em área de maior CE. Os cortes demonstraram eficiência no controle quando efetuados abaixo do nível da água, em drenos com profundidade da água acima de $30 \mathrm{~cm}$, tendo recuperado toda população e iniciada a emissão de espigas nas áreas cortadas acima do nível da água e em drenos, com profundidade da água menor que $30 \mathrm{~cm}$, em paneas dois meses. Todos os testes de viabilidade de aproveitamento apresentaram resultados positivos e promissores.

TíTULO: Caracterização cromossômica de algumas espécies e de hỉbridos interespecíficos do gênero Citrus

AUTORA: Maria Tereza Marquim N. Cornélio.

DATA: $\quad$ outubro de 1994

LOCAL: Universidade Federal Rural de Pernambuco - UFRPE

NIVEL: Mestrado

BANCA EXAMINADORA: Eugênio de França (orientador)

Tânia Maria Muniz de Arruda Falcão

Modesto Luceno Garcés.

RESUMO - Trabalho desenvolvido com o objetivo de caracterizar, citogeneticamente, com o uso de corantes fluorescentes, cromomicina $\mathrm{A}_{3}$ (CMA) e 4'-6- Diamioino 2. - Fenil - indol ${ }^{3}$ (DAPI) os cariótipos de seis espécies do gênero Citrus e de dois híbridos interespecificos e verificar a existência de cromossomos que possam ser utilizados como marcadores na identificação de híbridos, em programas de melhoramento. Foram estudadas as espécies $C$. aurantum, C. clementina, C, deliciosa, C. paradisi, C. reticulata e $C$. sinensis, e dois híbridos: $C$. parasidi x $C$. reticulata e $C$. sinensis X C. reticulata. Em todas as espécies de híbridos analisados, a maioria dos cromossomos apresentou blocos $\mathrm{CMA}^{+}$, distribuídos, principalmente, nas regiões teloméricas. Nenhum bloco DAPI+ foi observado nos cromossomos profásicos e metafásicos, embora no núcleo interfásico tenham sido observados pequenos cromocentros DAPI+. Quando analisados com a coloração DAPI, os blocos $\mathrm{CMA}^{+}$mostraram-se muito apagados ou pouco apagados em relação ao restante do cromossomo e, com base nestes dados, foram caracterizados dois tipos de heterocromatina: $\mathrm{CMA}^{+} / \mathrm{DAPI}{ }^{*}$ e $\mathrm{CMA}^{+} / \mathrm{DAPI}^{*}$, o tipo $\mathrm{CMA}^{+} / \mathrm{DAPI}^{*}{ }^{*}$ parecendo estar associado à região da constrição secundária. Cada cariótipo pode ser distinto pela presença ou ausência de determinados tipos cromossômicos ou pelo número de cromossomos com um mesmo padrão de bandas CMA. Os pares I e III, por apresentarem um padrão raro e diversificado, foram marcadores.

TíTULO: Estudo morfo-anatômico do sistema radicular de cinco espécies arbóreas de uma área de caatinga do Município de Alagoinha-PE 


\author{
AUTOR: Rivete Silva de Lima. \\ DATA: outubro de 1994 \\ LOCAL: Universidade Federal Rural de Pernambuco - UFRPE \\ NÍVEL: Mestrado \\ BANCA EXAMINADORA: José Elias de Paula (orientador) \\ Geraldo Mariz - UFRPE \\ Dilosa Carvalho de Alencar Barbosa - UFRPE
}

RESUMO - Nas pesquisas deste trabalho foi estudada a estrutura morfo-anatômica de cinco espécies arbóreas (Parapiptadenia zehtineri (Harms) M. P. L., Anadenanthera carocarpa (Benth.) Brenan Leguminosae; Astronium urundeuva Engl., e Spondias tuberosa Arr. Cam. - Anacardiaceae), de uma área de caatinga hipoxerófila do Estado de Pernambuco. A morfologia e a anatomia da raiz da planta jovem de cada espécie foram analisadas comparativamente com a morfologia e a anatomia da madeira da raiz da árvore correspondente. Através de processos e métodos estabelecidos para os trabalhos de campo e técnicas empregadas em trabalhos de anatomia geral e anatomia da madeira, inferiram-se resultados mostrando que, na fase jovem, a raiz principal das espécies analisadas apresentam tuberosidades, podendo ser mais ou menos acentuada, como em Spondias tuberosa e Schinopsis brasiliensis. Na fase arbórea, a tuberosidade perdura apenas nas raizes laterais de S. tuberosa. Raiz principal não foi detectada em planta na fase arbórea de $S$. tuberosa e A. macrocarpa. O sistema radicular das cinco espécies atingiu sempre pequena profundidade, que variou de $6 \mathrm{~cm}$ a $40 \mathrm{~cm}$, sendo distribuído horizontalmente à superfície do solo. As raizes principal e adventícias e laterais não indicaram caráter reprodutivo, isto é, não produzem brotos adventícios vegetativos nem florais. Presença constante de fibras gelatinosas nas cinco espécies tratadas e grande quantidade de substâncias de reserva representadas sobretudo por amido. Fibras gelatinosas presentes na madeira da raiz das espécies consideradas, exceto em A. urundeuva e $S$. tuberosa. A adaptação das espécies às condições xéricas foi demonstrada pela ocorrência de tuberosidade, presença de fibras gelatinosas, ausência ou redução de parênquima axial.

TíTULO: Uso da amostragem estratificada e análise de regressão na estimativa da produção de carnaúba Copernicia prunifera

AUTOR: Paulo Borbes da Cunha

DATA: outubro de 1994

LOCAL: $\quad$ Universidade Federal Rural de Pernambuco - UFRPE

NIVEL: Mestrado

BANCA EXAMINADORA: Marcos Antonio Amaral Passos

Carlos Ramirez Franco da Encarnação

Clodoaldo José da Anunciação Filho

RESUMO - O presente trabalho foi realizado na Fazendo Arial, localizada no município de Campo Maior-PI, compreendendo uma área de 229 ha de vegetação nativa de carnúba-Copernicia prunifera (Miller) H.E. Noore, ojetivando utilizar processos estatísticos para analisar e estimar a produção cerífera em populações de carnaúba, através de amostragem estratificada, expressando os parâmetros mais representativos do povoamento. A parcela considerada teve dimensōes de $20 \times 30 \mathrm{~m}$, totalizando uma área de $600 \mathrm{~m}^{2}$. No estrato I foram lançadas 30 parcelas nos meses de maio e junho; no estrato II, 20 parcelas na época seca, nos meses de Setembro/Outubro, para análise de modelos lineares múltiplos. A variável resposta considerada foi PP (peso do pó) e as variáveis independentes foram: HT (média da altura total das árvores), HF (média da altura do fuste das árvores), NF (média do número de folhas por árvores), DAP (média dos DAPs das árvores), CF (média do comprimento das folhas das árvores), PFS (média dos pesos das folhas secas das árvores), Narv (número de árvores por parcela), T (média de temperatura do ar no período de coleta dos dados, em ${ }^{\circ} \mathrm{C}$ ) e propriedades químicas e físicas do solo. $\mathrm{O}$ erro de amostragem adotado da amostra piloto foi de $5 \%$, e o obtido foi de $4,18 \%$. O limite confiança para a média de produção 
do pó cerífero para os estratos I 575,069 < mx <648,265 e 604,131 < mx <683,869 (g/parcela). Com base na densidade populacional e produção média por árvore, o limite de confiança para o estrato I foi: $17<\mathrm{mx}<19$ (árv./parcela), com produção de 31,949< mx < 36,016(g/árvore) e para o estrato II foi: $9<\mathrm{mx}$ $<11$ (árv. parcela). As equaçōes finais foram, para o estrato I o modelo linear simples: PP $=210,044+$ 22,373 Narv e para o estrato II a equação foi: $P P=(4,272+0,068 \text { Narv })^{4.032}$.

TíTULO: Variação florístico-vegetacional na região do Vale do Pajeú, Pernambuco

AUTORA: Elba Maria Nogueira Ferraz

DATA: outubro de 1994

LOCAL: Universidade Federal Rural de Pernambuco - UFRPE

NÍVEL: Mestrado

BANCA EXAMINADORA: Simon Joseph Mayo (orientador) - RBG, Kew

Marcelo Ramos da Fonseca

Margareth Ferreira de Sales

Maria Jesus Nogueira Rodal

RESUMO - Objetivando caracterizar a flora e vegetação lenhosa ocorrente nas altitudes de 1.100 e $900 \mathrm{~m}$ (brejo de altitude) e 700 e $500 \mathrm{~m}$ (caatinga), nos municípios de Serra Talhada e Triunfo-PE, foi realizado o levantamento florístico e a amostragem fitossociológica, através de parcelas, com a dimensão de $10 \times 20 \mathrm{~m}$, onde eram coletadas todas as espécies, exceto cipós e broméliaceas, cujas espécies tivessem diâmetros do caule, ao nível do solo, $>3 \mathrm{~cm}$ e altura total $>1 \mathrm{~m}$. Foram registradas 161 espécies distribuídas por 48 famílias. As famílias com maior número de espécies no brejo de altitude foram: Myrtaceae, Rubiaceae, Flacouticeae, Asteraceae e com 11, 7, 7 e 6 espécies cada, enquanto na caatinga foram Mimosaceae, Euphorbiaceae e Caesalpiniaceae com 9,8 e 5 espécies. A densidade e dominância totais variaram de 6.151 a $3.060 \mathrm{ind} . / \mathrm{ha} \mathrm{em} 1.100 \mathrm{e} 900 \mathrm{~m}$ e 56,8 a $30,61 \mathrm{~m}^{2} / \mathrm{ha}$ em 1.100 e $500 \mathrm{~m}$, respectivamente. A altura máxima média e a média por parcela e o diâmetro máximo médio e o diâmetro médio por parcela em $1.100,900,700$ e $500 \mathrm{~m}$ foram $11,13,7,9$ e $10,6 \mathrm{~m}, 4,5,8,4$ e $4 \mathrm{~m}$, e $43,44,9,51,2$ e $27,1 \mathrm{~cm}$ e $, 1211,1,11$ e $8,2 \mathrm{~cm}$. O índice de diversidade específica variou de $3,49 \mathrm{a} 1,83$ nats./ind. em $900 \mathrm{e} 700 \mathrm{~m}$.

TítUlO: Avaliação de três genótipos de mamona (Ricinus communis L.), em duas densidades de plantio no semiárido de Pernambuco

AUTORA: Aluízio Low Simões

DATA: novembro de 1994

LOCAL: Universidade Federal Rural de Pernambuco - UFRPE

NÍVEL: Mestrado

BANCA EXAMINADORA: Carlos Alberto de Oliveira Ventura (orientador)

José Geraldo Eugênio de França

Gothardo Marcon

RESUMO - Três cultivares de mamona foram avaliadas em duas densidades de plantio, nas localidades de Araripina e de Serra Talhada, na região semi-árida de Pernambuco. Foram conduzidos quatorze experimentos, sob o delineamento de blocos ao acaso, durante os anos de 1986 e 1992 . Os resultados obtidos mostraram haver diferença significativa entre as cultivares nas duas localidades isoladamente e quando avalizadas em conjunto, não foi obtida resposta diferencial significativa para as duas populações utilizadas nos espaçamentos. Na localidade de Araripina foi obtida maior produção média de sementes. Quando comparada à de Serra Talhada, independentemente da cultivar avaliada recomenda-se a cultivar sipeal-28. Para os ambientes estudados, no estudo de correlação ficou evidenciado que o parâmetro relativo a altura de plantas correlacionou-se de forma positiva $(p<0,01)$, com produção de sementes. Quanto aos demais parâmetros estes não apresentaram qualquer influência entre si e sobre a produtividade. 
TÍTULO: Taxonomia e número cromossômico de representantes da família Araceae em Pernambuco

AUTORA: Flávia Cartaxo Ramalho

DATA: fevereiro de 1995

LOCAL: Universidade Federal Rural de Pernambuco - UFRPE

NIVEL: $\quad$ Mestrado

BANCA EXAMINADORA: Marcelo Guerra (orientador) - UFPE

Simon Joseph Mayo - RBG, Kew

Geraldo Mariz - UFPE

RESUMO - A família Araceae possui uma grande variação no número cromossômico e outros caracteres citogenéticos. A análise citotaxonômica dessa família tem contribuído para a compreensão dos seus mecanismos evolutivos. A família Araceae está representada em Pernambuco por 47 espécies distribuídas em 19 gêneros. O gênero mais significativo para o Estado foi Philodendron, com 14 espécies, seguidos, por Anthurium, com nove espécies e Monstera com três espécies. Foram analisadas citogeneticamente 27 espécies e duas variedades, as quais apresentaram uma grande diversificação cromossômica. Das espécies analisadas, seis pertencentes a quatro gêneros foram relatadas pela primeira vez para o Nordeste, enquanto nove espécies de sete gêneros foram originais para Pernambuco. O maior número cromossômico foi encontrado em Aglaonema commutatu $(2 \mathrm{n}=\mathrm{ca}$. 120) e o menor, em Zomicarpa riedeliana $(2 \mathrm{n}=20)$. Nos dois maiores gêneros, a variação do número cromossômico foi: Philodendron $2 \mathrm{n}=30,32,34,40$ e 46 e Anthurium $2 n=30,40,48$ e 60 . O cariótipo das espécies analisadas foi assimétrico, com cromossomos acrocêntricos, submetacêntricos e metacêntricos. O núcleo foi sempre semi-reticulado. A análise citogenética das espécies de Anthurium, Colocasia, Caladium, Philodendron, Typhonium e Zomicarpa sugeriram que a evolução destes grupos foi acompanhada por diferentes mecanismos de transformação cariotípica.

TÍTULO: Bacillus spp. produtores de proteases: isolamento, caracterização e melhoramento de $B$. cereus $(\mathrm{C} 124)$ Frankland \& Frankland

AUTORA: Analucia Longman Mendonça

DATA: março de 1995

LOCAL: Universidade Federal Rural de Pernambuco - UFRPE

NÍVEL: Mestrado

BANCA EXAMINADORA: Rosa de Lima Ramos Mariano (orientadora)

João Lúcio de Azevedo

Joselito Medeiros

Ana Maria Souto Maior

RESUMO - Quarenta e quatro linhagens de Bacillus spp., obtidas de resíduos e derivados de cana-deaçúcar, sendo seis delas isoladas durante a realização deste trabalho, foram caracterizadas semiquantitativamente quanto à produção de proteases, através das médias dos índices enzimáticos, utilizando-se hemoglobina (meios ágar-hemoglobina e ágar-hemácia) e caseína (meio ágar-leite) como substratos. Após análise estatística, a linhagem Bacillus cereus $(\mathrm{C} 124)$, que apresentou melhor desempenho nos três meios, foi submetida a melhoramento genético com luz ultravioleta (UV) e através da curva de sobrevivência foi obtido o tempo de 28 " para uma sobrevivência de $30 \%$. Cinqüenta sobreviventes foram comparados semiquantitvamente com a linhagem selvagem $B$. cereus $(\mathrm{C} 124)$ quanto à produção de proteases, como anteriormente citado. Cinco mutantes, C124UV18, C124UV29, C124UV35, C124UV47, que apresentaram médias dos índices enzimáticos maiores que a linhagem selvagem, bem como esta última, foram avaliados quanto aos perfis de proteínas totais e esterases, através de eletroforese em gel de poliacrilamida (PAGE). Padrões eletroforéticos para proteínas totais da linhagem selvagem e dos mutantes selecionados 
apresentaram diferentes perfis em número, posição e intensidade das bandas, enquanto que, para esterases, a variabilidade ocorreu apenas com relação à intensidade.

TíTULO: Parâmetros oceanográficos e distribuição das espécies e bosques de mangue do Estuário do Rio Paripe-PE

AUTORA: Joana D'Arc V. Silva

DATA: maio de 1995

LOCAL: Universidade Federal Rural de Pernambuco - UFRPE

NÍVEL: $\quad$ Mestrado

BANCA EXAMINADORA: Carmen Medeiros (orientadora)

Christian Von Dorrien

Everardo V.S.B. Sampaio

Silvio José de Macedo

RESUMO - Este trabalho objetivou caracterizar o ambiente de manguezal e correlacionar a composição e distribuição das espécies e bosques de mangue com variáveis ambientais. O estudo ocorreu no estuário do rio Paripe, sul da llha de Itamaracá-PE, de 1992 a 1993 em períodos chuvoso e de estiagem, e abrangeu a caracterização das marés, da composição textural do solo e de seu teor de carbono orgânico, da salinidade das águas e o mapeamento da distribuição, estrutura e fisionomia da vegetação. Um mapa detalhado para a área foi elaborado com base em imagens de satélites, fotos aéreas e observações in situ. O manguezal ocupa 37,3 ha (29,4ha de mangue $+7,9$ ha de canais e clareiras). As marés são semidiurnas com amplitudes de sizigia de 1,90, 1,56 e 1,35m no estuário baixo, médio e superior, respectivamente. Boa parte do estuário permanece $25-75 \%$ do tempo inundada, com a faixa marginal e o trecho superior do estuário sofrendo inundações menos frequentemente que sua porção inferior e central. Ao longo do sistema, prevalecem os solos arenosos ( $80-85 \%$ areia), com solos franco e franco arenoso (45-60\% areia) no baixo estuário. A concentração de carbono orgânico está associada ao tempo de imersão e, principalmente, à

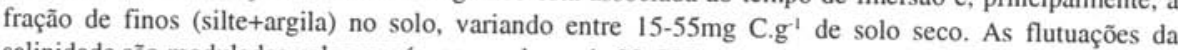
salinidade são moduladas pelas marés, com valores de $33-55 \%$ na preamar e de $11-34 \%$ na baixa-mar em quase em todo o estuário. A floresta é do tipo reibeirinho e apresenta dois estratos $(2-7$ e $7-14 \mathrm{~m})$ vegetacionais. $\mathrm{O}$ estrato superior está formado por indivíduos adultos de Rhizophora mangle L., e o inferior, por jovens de $R$. mangle, Laguncularia racemosa Gaernt. f., Conocarpus erectus, $L$. racemosa está restrita às bordas de ilhotas e em áreas com salinidades mais baixas e menos variáveis. C. erectus ocorre em áreas planas, sujeitas a inundaçōes pouco frequentes e associado a solo arenoso. A zonação das espécies parece estar principalmente ligada à topografia e às características do solo (granulometria e teor de $\mathrm{C}$ orgânico).

TÍTULO: A subfamilia Echitoideae K. Schum. (Apocynaceae) no Estado de Pernambuco - Brasil

AUTORA: Ângela Maria de Miranda Freitas

DATA: $\quad$ setembro de 1995

LOCAL: Universidade Federal Rural de Pernambuco - UFRPE

NÍVEL: Mestrado

BANCA EXAMINADORA: João Semir (orientador) - UNICAMP

Laise de Holanda Cavalcanti Andrade - UFPE

Simon Joseph Mayo - RBG, Kew

Sônia Maria Barreto Pereira - UFRPE

RESUMO - Este trabalho trata do levantamento taxonômico dos representantes nativos da subfamília Echitoideae K.Schum. (Apocynaceae) ocorrentes em Pernambuco. O material foi coletado nas diversas zonas fitogeográficas, durante o período de 1991 a 1995. Foram também analisadas exsicatas depositadas 
nos diversos herbários locais e nacionais. São fornecidas para cada espécie descrição, ilustração, complementadas com comentários taxonômicos, fenológicos e distribuição geográfica. Em Pernambuco constatou-se a ocorrência de sete gêneros, com o total de 21 espécies. São propostas duas novas espécies para os gêneros Peltastes e Mandevilla. Prestonia annularis (L.f.) G. Don, Mandevilla sellowii (Müll. Arg.) Woodson, constituem referências novas para o Nordeste; Allamanda doniana Müll. Arg., M. lasiocarpa (A. DC.) Malme, M. scabra (Roem. \& Schult.) K. Schum., Forsteronia glabrescens Müll. Arg., Prestonia coalita (Vell.) Woodson, P. bahiensis Müll. Arg. e Odontadenia lutea (Vell.) Markgr. são referências novas para Pernambuco. O gênero Mandevilla foi o de maior representação, com oito espécies e Peltastes e Odontadenia foram monotípicas para a área em estudo. Mandevilla tenuifolia (Mikan) Woodson e Allamanda blanchetii A. DC. apresentaram a maior distribuição geográfica, enquanto que Prestonia pickelii Markgr., P. annularis, Odontadenia lutea, Mandevilla sellowii e Mandevilla sp. nov. foram registradas em uma única coleta. A ocorrência de Allamanda puberula A. DC. e Mandevilla sp. nov. é restrita à região de caatinga, Mandevilla moricandiana (A. DC.) Woodson foi coletada exclusivamente em vegetação de restinga e Mandevilla sellowii, Prestonia annularis e Forsteronia glabrescens só foram registradas para brejo de altitude.

TíTULO: Análise genética multivariada numa população de milho (Zea mays L.) dentado composto do estado de Pernambuco

AUTOR: Gerson Quirino Bastos

DATA: dezembro de 1995

LOCAL: Universidade Federal Rural de Pernambuco - UFRPE

NIVEL: Mestrado

BANCA EXAMINADORA: Margarida Agostinho Lemos (orientadora)

Carlos Alberto D'Oliveira Ventura

Elto Eugênio Gomes e Gama

Gothardo Marcon

Mário de Andrade Lira

RESUMO - Duzentas progênies de meios irmãos de milho (Zea mays L.) Dentado Composto, do Acordo Empresa Pernambucana de Pesquisa Agropecuária (IPA), Universidade Federal Rural de Pernambuco (UFRPE) e Empresa Brasileira de Pesquisa Agropecuária (EMBRAPA), foram estudadas para realização de uma análise genética multivariada. O objetivo principal foi o de selecionar as 50 melhores progênies através da análise de trilha (path coefficient) e de agrupamento genético, com base na Distância Ge-neralizada de Mahalanobis. Foram conduzidos dois experimentos, no ano agrícola 1992/1993, em deli-neamento de látice simples $10 \times 10$, com duas testemunhas. Na análise da trilha, constatou-se que o caráter NE predominou na expressão dos maiores efeitos positivos, diretos e indiretos, sobre PG. Pela análise de agrupamento de genótipos, com o método de otimização de Tocher e a partir da Distância Generalizada de Mahalanobis, foram compostos 13 diferentes grupos de progênies geneticamente mais aproximadas. As maiores médias de PG e menores notas médias de dano de $\mathrm{HZ}$ e SF, encontradas entre as progênies geneticamente o mais aproximadas possível, revelaram-se ser uma referência confiável para a continuidade da seleção em novos ciclos de recorrência da população de milho Dentado Composto de Pernambuco.

TÍTULO: Avaliação do modo de reprodução e de caracteres quantitativos em 20 acessos de açaizeiro (Euterpe oleracea Mart., Arecaceae) em Belém-PA

AUTOR: $\quad$ Maria do Socorro Padilha de Oliveira

DATA: dezembro de 1995

LOCAL: Universidade Federal Rural de Pernambuco - UFRPE

NÍVEL: Mestrado

BANCA EXAMINADORA: Margarida Agostinho Lemos (orientadora) 
Elton Oliveira dos Santos

Isabel Cristina S. Machado

Milton G. da C. Mota

RESUMO - Avaliaram-se o modo de reprodução de dezesseis caracteres quantitativos em 20 acessos de açaizeiro da coleção de germoplasma do CPATU, Belém-PA, durante dezenove meses. Na reprodução analisaram-se a duração das fases masculina e feminina e os intervalos ou sobreposições na mesma inflorescência $(\mathbf{n})$, entre inflorescências no estipe $(\mathbf{n}+\mathbf{1})$, e entre inflorescências na touceira $(\mathbf{m})$. Nos caracteres: número de estipes/planta (NEP), número de folhas (NF), coprimento de bainha foliar (CBF), altura do estipe (AE), comprimento entrenó (CEN), circunferência do estipe (CAP), maturação dos frutos (MF), número de cachos/planta (NCP), peso do cacho (PC), peso de frutos/cacho (PF), peso médio do fruto (PMF), número de frutos/cacho (NFC), número de ráquilas/cacho (NRA), comprimento do ráquis do cacho ( CR), rendimento de frutos/cacho (CFC) e produção de frutos/planta (PFP), estudaram-se a variação fenotípica através de estatística simples e do delineamento inteiramente casualizado com 20 tratamentos e cinco repetiçōes; a correlação de Pearson e o coeficiente caminhamento dos principais componentes da produção de frutos. Dezessete acessos apresentaram intervalos para $(\mathbf{n}),(\mathbf{n + 1})$ e $(\mathbf{m})$ e os demais sobreposições de um ou dois dias em (n) ou (m) e por serem curtos, os acessos foram considerados como alógamos não obrigatórios. Os caracteres NEP, NCP, PC, PF, NFC e PFP mostraram elevada variação fenotípica, com CV acima de $36,61 \%$, podendo serem explorados no melhoramento dessa palmeira. Os acessos 426Ch, $444 \mathrm{Mu}$ e $463 \mathrm{Br}$ oriundos de Chaves, Muaná e Breves, respectivamente, foram os mais variáveis para treze caracteres, ficando o $439 \mathrm{Mu}$ com a menor variação em dez caracteres. Os acessos foram semelhantes para NF, DAP e RFC. O $465 \mathrm{Br}$ teve o melhor desempenho, produzindo $29,24 \mathrm{~kg}$ de frutos, porém não diferiu do $438 \mathrm{Mu}$ e $468 \mathrm{Br}$ que alcançaram $14,32 \mathrm{Kg}$, respectivamente. As correlaçōes entre os caracteres: PC $x$ NFC, PFP x NCP, NFC xPF e PC x PF foram positivas e de fortes magnitudes e podem ser úteis na seleção de genótipos superiores. O NCP e PF exerceram os maiores efetios diretos positivos, com o PF tendo influência marcante nos efeitos indiretos, ambos considerados como principais componentes na avaliação de açaizeiros para frutos.

TíTULO: Clorofíceas bentônicas do litoral sul do Estado de Pernambuco (Brasil)

AUTOR: José Augusto Pereira Angeiras

DATA: Dezembro de 1995

LOCAL: Universidade Federal Rural de Pernambuco - UFRPE

NÍVEL: Mestrado

BANCA EXAMINADORA: Sonia Maria Barreto Pereira (orientadora)

Claudia Castelo Branco Chamixaes

Enide Eskinazi Leça

Leonor Costa Maia

RESUMO - Estudos sobre clorofíceas marinhas bentônicas do litoral sul do Estado de Pernambuco, da praia do Pina (Município do Recife) até a praia de São José da Coroa Grande, (Município de Barreiros) foram realizados objetivando identificar as espécies, a distribuição espacial e temporal de cada uma. ocorrência por tipo de substrato. Estes estudos foram feitos no período de março/1990 a agosto/1992, abrangendo 5 estações de coleta. Amostragens trimestrais foram efetuadas em cada estação, nos substratos rochosos, arenoso e de macroalgas. Em laboratório, as amostras foram preservadas com formol a $4 \%$, neutralizado com bórax. Estudos taxonômicos basearam-se no aspecto geral de cada exemplar além de análises de cortes transversais do talo em estereomicroscópio. Foram identificadas 10 famílias, 5 ordens e 28 espécies, com 3 variedades 3 formas. Os táxons com maior distribuição na área foram Ulva lactuca, Caulerpa racemosa var. racemosa. Bryopsis pennata e Halimeda opuntia. Entre os táxons registrados, 4 só ocorreram no mesolitoral e apenas 6 no infralitoral, os demais foram comuns aos dois andares. Ulva fasciata, U. lactuca, Caulerpa mexicana. C. sertularioides, C. cupressoides var. lycopodium, C. racemo- 
sa var. racemosa, C. racemosa var. occidentalis, Bryopsis pennata e Halimeda opuntia foram identificados no três tipos de substratos.

TÍTULO: Morfo-anatomia comparativa de indivíduos distintos de Tabebuia aurea (Manso) Bentham \& Hooker F. ex S. Moore (Bignoniaceae)

AUTOR: $\quad$ Maria das Dores Melo

DATA: dezembro de 1995

LOCAL: Universidade Federal Rural de Pernambuco

NIVEL: Mestrado

BANCA EXAMINADORA: Geraldo Mariz (orientador) - UFPE

Maria das Graças Medina Arraes - UFPI

Izaíras Padovan - UFPE

Maizareth Ferreira Sales - UFRPE

RESUMO - Neste estudo, fez-se uma análise comparativa de caracteres morfo-anatômicos da raiz, caule, folha e grão de pólen de indivíduos distintos de Tabebuia aurea (Manso) Bentham \& Hooker F. ex S. Moore (Bignoniaceae), espécie arbórea ocorrente em regiōes de caatinga hiperxerófila dos Estados de Pernambuco e Rio Grande do Norte. Para diferenciar os indivíduos, utilizou-se um caráter morfológico, o tamanho da folha, denominando-se Tabebuia 1 e Tabebuia 2. Foram escolhidas três áreas para coleta do material botânico, sendo que uma das áreas foi designada para observaçōes das características morfológicas, ecológicas e fenológicas. As sementes foram coletadas no local, a fim de serem postas a germinar no laboratório e em casa de vegetação, com o propósito de estudar o seu desenvolvimento até sete meses de idade. Verificou-se, um curto tempo de germinação para estes indivíduos, tanto em laboratório quanto em casa de vegetação. As observações anatômicas da raiz e do caule foram feitas em plântulas e plantas jovens. A morfologia da raiz, do caule, da folha e dos grãos de pólen foram verificadas tanto em indivíduos jovens quanto em indivíduos adultos, utilizando-se das técnicas usuais. As maiores diferenças anatômicas entre os indivíduos Tabebuia 1 e Tabebuia 2 foram encontradas na raiz. O cilindro central revelou estrutura tetrarca para o indivíduo Tabebuia 1 e pentarca para o indivíduo Tabebuia 2. Com referência ao caule, a estrutura anatômica nos dois indivíduos é bastante similar, não evidenciando diferenças importantes. Morfologicamente, a folha de Tabebuia 1 assemelhase a Tabebuia 2, apenas difere no tamanho. Quanto às estruturas internas, a folha é isobilateral e dorsiventral, anfistomática, com pêlos escamiformes e nectários, providas de esclereídes. O grão de pólen de Tabebuia 1 tem a forma prolata esferoidal, âmbito circular e subtriangular enquanto que Tabebuia 2, o grão tem a forma subprolata.

TÍTULO: Morfo-Anatomia de seis espécies de Pilosocereus Byles \& Rowlay (Cactaceae)

AUTOR: Delmira da Costa Silva

DATA: maio de 1996

LOCAL: $\quad$ Universidade Federal Rural de Pernambuco - UFRPE

NÍVEL: Mestrado

BANCA EXAMINADORA: José Luiz de Hamburgo Alves (orientador) - UFPE

Maria das Graças Medina Arraes - UFPI

Isabel Cristina Sobreira Machado - UFPE

RESUMO - Foi proposta do trabalho o estudo de seis espécies de Pilosocereus, ocorrentes em Pernambuco, visando estabelecer parâmetros anatômicos como subsídios à taxonomia, além de informações sobre a estrutura interna das espécies, em função de adaptação ao ambiente onde ocorrem. A pesquisa compreendeu aspectos morfológicos e análise da estrutura interna de órgãos vegetativos, levando-se em consideração características celulares e contextos de tecidos permantentes, vascularização, distirbuição e 
padronização estomática, concernente à família. Utilizando-se a metodologia usual em tratamento de anatomia geral e outras técnicas oportunas, obtiveram-se resultados que indicaram que a condição xerófila das Cactaceae se reflete em muitos dos aspectos morfológicos e estruturais dessas plantas. A associação de parâmetros vasculares e organização morfológica, tais como número de feixes vasculares em correspondência ao número de costelas do eixo caulinar, não traduz apenas estratégia do comportamento fisioecológico das espécies, mas oferecem, também, subsídios taxonômicos a esse grupo de plantas. A tipificação e densidade estomática é um outro segmento que pode ser adicionado ao parâmetro anteiror, quanto ao auxílio à taxonomia e esclarecimento do comportamento fisiológico do grupo. A delimitação entre córtex e cilindro vascular pode ser estabelecida a partir da estrutura secundária do eixo aéreo das plantas jovens, quando uma bainha amilífera foi detectada entre córtex e cilindro central.

TíTULO: Estudos taxonômicos do gênero Capparis L. (Capparaceae Juss.) em Pernambuco - Brasil AUTORA: Maria Bernadete Costa e Silva

DATA: $\quad$ setembro de 1996

LOCAL: Universidade Federal Rural de Pernambuco - UFRPE

NÍVEL: Mestrado

BANCA EXAMINADORA: Margareth Ferreira de Sales (orientadora)

Enide Eskinazi Leça

Simon Joseph Mayo

Maria de Jesus Nogueira Rodal

RESUMO - O trabalho consiste dos estudos taxonômicos do gênero Capparis L. no Estado de Pernambuco, Brasil. Foi baseado na análise comparativa de espécimes obtidos em viagens de coleta de 1992 a 1994 e de materiais herborizados. Foram feitos ainda, estudos palinológicos em microscopia óptica e eletrônica de varreduara em cinco espécies e contagem cromossômica em quatro espécies. Foram elaboradas chaves de identificação para as espécies, além de descrições, comentários, distribuição geográfica e ilustrações para cada espécie. Constararam-se sete espécies para Pernambuco: Capparis cynophallophora L., C. flexuosa (L.) L., C. lineata Dombey ex Pers., C. nectarea Vell., C. baducca L., C. jacobinae Moric ex Eichler, C. yco (Mart.) Eichler. Foram referidas pela primeira vez para Pernambuco: $C$. lineata, $C$. nectarea e $C$. baducca. Foram corrigidos os nomes das autoridades de $C$. jacobinae e $C$. yco. Os grãos de pólen apresentaram diferenças conspícuas entre as espécies e a análise cromossômica revelou números diferentes confirmando as identidades de $C$. cynophallophora e $C$. flexuosa. Apresentaram distribuição exclusiva na zona da mata: $C$. lineata, $C$. nectarea e $C$. baducca; desde a zona da mata e/ou litoral até a caatinga, $C$. cynophallophora e $C$. flexuosa e as espécies $C$. jacobinae e $C$. yco são exclusivas da caatinga.

\section{Universidade Federal do Rio Grande do Sul}

TítUlO: Ontogenia da antera e do rudimento seminal de Tabebuia pulcherrima Sandwith (Bigno-

AUTOR: Nelson Sabino Bittencourt Júnior

DATA: $\quad$ outubro de 1995

LOCAL: Universidade Federal do Rio Grande do Sul - UFRGS

NÍVEL: Mestrado

BANCA EXAMINADORA: Jorge E. de Araújo Mariath (orientador) - UFRGS

Paulo Luiz de Oliveira - UFRGS

Bruno Edgard Irgang - UFRGS

Alfredo Elio Cocucci - Univ. Nac. de Córdoba, AR 